\title{
Analisis Diskriminan dalam Menentukan Fungsi Pengelompokan Kabupaten/Kota di Indonesia berdasarkan Indikator Indeks Pembangunan Manusia
}

\author{
Nurhasanah ${ }^{1 *}$, Nany Salwa ${ }^{2}$, Lyra Ornila ${ }^{3}$, Fitriana AR ${ }^{4}$, \\ Amiruddin Hasan ${ }^{5}$ \\ 1,2,3,4 Prodi Statistika, Universitas Syiah Kuala, Provinsi Aceh, Indonesia. \\ 5 Prodi Ilmu Pendidikan Ekonomi, Universitas Syiah Kuala, Provinsi Aceh, \\ Indonesia.
}

\begin{abstract}
Abstrak. Indeks Pembangunan Manusia (IPM) merupakan salah satu ukuran yang digunakan untuk mengukur keberbasilan pembangunan manusia di suatu daerah. Terdapat beberapa indikator yang digunakan untuk penyusun nilai IPM. Sebelumnya telah dilakukan pengelompokan kabupaten/kota berdasarkan indikator IPM. Pengelompokan tersebut dilakukan dengan menggunakan analisis K-means cluster dengan 4 kategori, yaitu kabupaten/kota yang memiliki nilai indikator IPM rendah, sedang, tinggi, dan sangat tinggi. Dari hasil penentuan kategori indikator IPM suatu daerah diperlukan sebuah fungsi yang dapat digunakan untuk mengklasifikasikan suatu objek ke dalam salah satu dari kategori nilai indikator IPM. Penyusunan fungsi klasifikasi tersebut dilakukan dengan menggunakan analisis diskriminan. Hasil yang diperoleh dari analisis diskriminan adalah terdapat 10 peubah atau indikatoryang masuk ke dalam fungsi diskriminan. Fungsi diskriminan yang dihasilkan cukup baik dalam mengklasifikasikan setiap kelompok dengan tingkat keberbasilan lebih dari 85\% dan fungsi diskriminan tersebut didiukung dengan tingkat keberbasilan validasi yang cukup baik yaitu dengan ketepatan klasifikasi sebesar 93,20\%.
\end{abstract}

Kata kunci: Indeks Pembangunan Manusia; analisis diskriminan; Indonesia.

\begin{abstract}
The Human Development Index (HDI) is a measure used to measure the success of human development in an area. There are several indicators used to compile the HDI value. Previously, regencies/cities were grouped based on the HDI indicator. The grouping is done using K-means cluster analysis with 4 categories, namely regencies/cities that have low, medium, high, and very high HDI indicator values. From the results of determining the category of the HDI indicator in an area, we need a function that can be used to classify an object into one of the HDI indicator value categories. The compilation of the classification function is carried out using discriminant analysis. The results obtained from the discriminant analysis are that there are 10 variables or indicators that fall into the discriminant function. The resulting discriminant function is quite good in classifying each group with a success rate of more than $85 \%$ and the discriminant function is supported by a fairly good validation success rate, namely with a classification accuracy of $93.20 \%$.
\end{abstract}

Keywords: Human Development Index; discriminant analysis; Indonesia. 


\section{Pendahuluan}

Pembangunan merupakan salah satu upaya yang dilakukan pemerintah untukmenciptakan masyarakat yang makmur dan sejahtera. Salah satu ukuran yang digunakan untuk mengukur keberhasilan pembangunan di suatu wilayah adalah dengan menggunakan nilai Indeks Pembangunan Manusia. Selama ini, tentunya pemerintah pusat dan daerah telah melaksanakan berbagai program untuk meningkatkan nilai IPM di setiap wilayah di Indonesia. Program pembangunan yang dilaksanakan pemerintah selama ini ternyata menimbulakan kesenjangan yang cukup tinggi antar daerah. Hal ini dapat dilihat dari perbandingan nilai IPM tertinggi dengan nilai IPM terendah. Menurut BPS (2016), nilai IPM tertinggi pada tahun 2015 dimiliki oleh Kota Yogyakarta dengan capaian nilai IPM sebesar 84,56, sedangkan nilai IPM terendah dimiliki oleh Kabupaten Nduga dengan capaian nilai IPM sebesar 25,47.

Sebelumnya telah dilakukan penelitian untuk mengklasifikasikan 514 kabupaten/kota di Indonesia menjadi daerah yang memiliki nilai indikator IPM rendah, sedang, tinggi, dan sangat tinggi dengan menggunakan analisis cluster K-means. Sebanyak 20 (3,89\%) kabupaten diklasifikasikan menjadi daerah yang memiliki nilai indikator IPM rendah, 148 $(28,79 \%) \quad$ kabupaten/kota diklasifikasikan menjadi daerah yang memiliki nilai indikator IPM sedang, 258 (50,20\%) kabupaten/kota diklasifikasikan menjadi daerah yang memiliki nilai indikator IPM tinggi, dan $88(17,12 \%)$ kabupaten/kota diklasifikasikan menjadi daerah yang memiliki nilai indikator IPM sangat tinggi. Terdapat 10 indikator yang digunakan dalam penelitian sebelumnya untuk menentukan kategori indikator IPM suatu daerah.

Dari hasil penentuan kategori indikator IPM suatu daerah diperlukan sebuah fungsi yang dapat digunakan untuk mengklasifikasikan suatu objek ke dalam salah satu dari kategori nilai indikator IPM. Penyusunan fungsi klasifikasi tersebut dilakukan dengan menggunakan salah satu analisis statistika, yaitu dengan menggunakan analisis diskriminan.

\section{Tinjauan Kepustakaan}

\section{Indeks Pembangunan Manusia (IPM)}

Indeks Pembangunan Manusia (IPM) merupakan suatu ukuran yang digunakan untuk mengukur keberhasilan pencapaian pembangunan sumber daya manusia antar negara, selain itu IPM juga digunakan untuk membandingkan keberhasilan pencapaian pembangunan manusia antar wilayah. IPM diperkenalkan pertama kali pada tahun 1990 oleh UNDP (United Nation Development Programme). Perhitungan IPM didasarkan pada indeks komposit yang terdiri dari indeks kesehatan, indeks pendidikan, dan indeks ekonomi. Ketiga indeks tersebut, masing-masing terdiri dari indikator-indikator penyusun yang digunakan untuk menghitung nilai IPM (BPS, 2015).

Penelitian sebelumnya mengkategorikan wilayah di Indonesia berdasarkan indikator IPM dengan menggunakan analisis clusterK-Means. Analisis clusterK-Means merupakan suatu analisis statistika yang digunakan untuk mengelompokan suatu objek berdasarkan kemiripan yang dimilikinya. Ukuran kemiripan suatu objek dapat diukur dengan suatu ukuran jarak. Jarak yang paling umum digunakan adalah jarak Euclidean. Jarak Euclidean antara dua objek $P$ dan $Q$ dengan koordinat $P=\left(x_{1}, x_{2}, \ldots, x_{\mathrm{p}}\right)$ dan $Q=\left(y_{1}, y_{2}, \ldots\right.$ ,$\left.y_{\mathrm{p}}\right)$ diukur dengan menggunakan persamaan berikut (Johnson dan Wichern, 2007).

$d(P, Q)$

$=\sqrt{\left(x_{1}-y_{1}\right)^{2}+\left(x_{2}-y_{2}\right)^{2}+\cdots+\left(x_{p}-y_{p}\right)^{2}}$

Suatu objek akan berada dalam satu kelompok apabila memiliki jara yang dekat dan memiliki jarak yang jauh dengan objek yang berada pada kelompok lainnya (Mattjik dan Sumertajaya, 2011).

\section{Asumsi Analisis Diskriminan}

Analisis diskriminan bertujuan untuk mengklasifikasikan atau mengelompokan observasi atau objek tertentu ke dalam kelompok berdasarkan variabel pembeda (discriminating variables). Analisis diskriminan digunakan ketika variabel dependen bersifat kategorik dengan variabel independen bersifat numerik/ kategorik. Dalam melakukan analisis diskriminan, terdapat beberapa asumsi yang harus dipenuhi (Hair et al, 
2010). Asumsi yang harus dpenuhi dalam analisis diskriminan adalah sebagai berikut:

\section{Uji Kenormalan Ganda}

Menurut Johnson dan Wichern (2007), untuk pengujian data berdistribusi normal ganda dapat dilakukan dengan membuat plot jarak kuadrat Mahalanobis $\left(d_{j}^{2}\right)$ dengan nilai chi-square $\left(\chi_{p}^{2}\left(\left(j-\frac{1}{2}\right) / n\right)\right.$. Jarak kuadarat Mabalanobis untuk setiap objek dapat dihitung dengan menggunakan persamaan sebagai berikut:

$$
d_{j}^{2}=\left(\mathbf{x}_{j}-\overline{\mathbf{x}}\right)^{\prime} \mathbf{S}^{-1}\left(\mathbf{x}_{j}-\overline{\mathbf{x}}\right), j=1,2, \ldots, n
$$
dimana:

$d_{j}^{2}=$ jarak kuadrat Mabalanobis

$\mathbf{x}_{j}=$ vektor pengamatan ke- $j$

$\overline{\mathbf{x}}=$ vektor rata-rata

$\mathbf{S}^{-1}=$ invers matriks peragam $\mathbf{S}$

Setelah nilai $d_{j}^{2}$ didapatkan, kemudian nilai $d_{j}^{2}$ diurutkan dari yang terkecil ke yang terbesar $\left(d_{1}^{2} \leq d_{2}^{2} \leq \ldots \leq d_{n}^{2}\right)$, selanjutnya $d_{j}^{2}$ diplotkan dengan nilai chi-square $\chi_{p}^{2}\left(\left(j-\frac{1}{2}\right) / n\right)$, dimana $j$ $=1,2, \ldots, n$ dan $p=$ banyaknya peubah.Apabila plot $d_{j}^{2}$ dengan $\chi_{p}^{2}\left(\left(j-\frac{1}{2}\right) / n\right)$ dapat didekati dengan garis lurus dan ada lebih dari 50\% nilai $d_{j}^{2}<\chi_{0,5, p}^{2}$ maka dapat disimpulkan bahwa data menyebar normal ganda.

\section{Uji Kesamaan Matriks Peragam}

Menurut Mattjik dan Sumertajaya (2011), statistik uji yang digunakan untuk menguji kesamaan matriks peragam adalah statistik uji Box's M. Berikut adalah persamaan untuk statistik uji Box's $M$.

$$
\begin{array}{r}
-2 \ln \lambda^{*}=(n-g) \ln \left|\mathbf{S}_{p l}\right| \\
-\sum_{\substack{j=1 \\
-1) \ln \left|\mathbf{S}_{j}\right|}}\left(n_{j}\right.
\end{array}
$$

dimana:

$$
\lambda^{*}=\frac{\prod_{j=1}^{g}\left|\mathbf{S}_{j}\right|^{\left(n_{j}-1\right) / 2}}{\left|\mathbf{S}_{p l}\right|^{(n-g) / 2}}
$$

$g$ = banyaknya kelompok

$n_{j}=$ banyaknya observasi pada kelompok ke- $j$

$\mathbf{S}_{p l}=$ matriks peragam gabungan

$\mathbf{S}_{j}=$ matriks peragam kelompok ke-j
Apabila hipotesis nol tidak dapat ditolak, maka 2 ln $\lambda^{*} / b$ akan mengikuti sebaran $F$ dengan derajat bebas $v_{1}$ dan $v_{2}$ pada taraf nyata $a$, dimana: $v_{1}=\left(\frac{1}{2}\right)(g-1) p(p+1), \quad v_{2}=\frac{v_{1}+2}{\left(a_{2}-a_{1}^{2}\right)}$, $b=\frac{v_{1}}{\left(1-a_{1}-\frac{v_{1}}{v_{2}}\right)}$

$a_{1}=\frac{2 p^{2}+3 p-1}{6(g-1)(p+1)}\left[\sum_{j=1}^{g} \frac{1}{\left(n_{j}-1\right)}-\frac{1}{(n-g)}\right]$, $a_{2}=\frac{(p-1)(p+2)}{6(g-1)}\left[\sum_{j=1}^{g} \frac{1}{\left(n_{j}-1\right)^{2}}-\frac{1}{(n-g)^{2}}\right]$

Jika $-2 \ln \lambda^{*} / b \leq F_{a, v 1, v 2}$ maka tidak dapat menolak $\mathrm{H}_{0}$ dan dapat disimpulkan bahwa antar kelompok memiliki matriks peragam yang sama. Apabila $-2 \ln \lambda^{*} / b \geq F_{a, v 1, v 2}$ maka $\mathrm{H}_{0}$ dapat ditolak sehingga matriks peragam antar kelompok tidak sama.

\section{Uji Beda Vektor Nilai Rata-Rata}

Statistik uji yang digunakan dalam pengujian vektor nilai rata-rata adalah statistik uji Wilk's $\Lambda$. Persamaan statistik uji Wilk's $\Lambda$ adalah sebagai berikut.

$$
\begin{array}{r}
\Lambda=\frac{|\mathbf{W}|}{|\mathbf{B}+\mathbf{W}|} \\
\begin{array}{r}
\mathbf{W}=\sum_{i=1}^{g}\left(n_{i}-1\right) \mathbf{S}_{i} \\
=\left(n_{1}+n_{2}+\cdots+n_{g}\right. \\
-g) \mathbf{S}_{p l}
\end{array} \\
\mathbf{B}=\sum_{i=1}^{g}\left(\overline{\mathbf{x}}_{\mathrm{i}}-\overline{\mathbf{x}}\right)\left(\overline{\mathbf{x}}_{\mathrm{i}}-\overline{\mathbf{x}}\right)^{\prime}
\end{array}
$$

Statistik uji Wilk's $\Lambda$ dapat didekati dengan statistik uji $F$. Nilai $F_{\text {statistiti }}$ diperoleh dengan persamaan sebagai berikut:

$$
F=\left(\frac{1-\Lambda^{1 / t}}{\Lambda^{1 / t}}\right)\left(\frac{d f_{2}}{d f_{1}}\right)
$$

Jika nilai $F$ hitung lebih besar dari $F_{\alpha, d f 1, d f 2}$ maka $\mathrm{H}_{0}$ ditolak. Hal ini berarti terdapat perbedaan nilai vektor rata-rata antar kelompok. Oleh karena itu, fungsi pembeda (discriminant) layak dibentuk (Rencher, 2002).

\section{Fungsi Diskriminan}

Fungsi diskriminan merupakan kombinasi linear dari peubah-peubah asal yang akan menghasilkan cara terbaik dalam pemisahan kelompok. Pengklalsifikasian kelompok dapat menggunakan fungsi diskriminan sebagai 
berikut:

$$
Y_{i}=\overline{\mathbf{X}}_{i}^{\prime} \mathbf{S}_{\text {pooled }}^{-1} \mathbf{X}-\frac{1}{2} \overline{\mathbf{X}}_{i}^{\prime} \mathbf{S}_{\text {pooled }}^{-1} \overline{\mathbf{X}}_{i}+\ln \left(p_{i}\right)
$$

dimana:

$\mathbf{X}=$ peubah yang diidentifikasi dalam fungsi diskriminan

$\overline{\mathbf{X}}_{i} \quad=$ vektor rata-rata untuk kelompok ke- $i$

$\mathbf{S}_{\text {pooled }}=$ matriks varian kovarian gabungan

$p_{i} \quad=$ probabilitas awal keanggotaan kelompok

Objek baru $\mathbf{X}$ akan masuk ke kelompok ke- $k$, jika $Y_{k}=\max \left(Y_{1}, Y_{2}, \ldots, Y_{g}\right)$ (Johnson dan Wichern, 2007).

\section{Tingkat Ketepatan Klasifikasi}

Tingkat ketepatan klasifikasi dapat dilihat menggunakan tabel ketepatan klasifikasi berikut:

Tabel 1. Tabel ketepatan klasifikasi

\begin{tabular}{cccc}
\hline Actual & Jumlah & \multicolumn{2}{c}{ Predicted Group } \\
\cline { 3 - 4 } Group & Observasi & 1 & 2 \\
\hline 1 & $n_{1}$ & $n_{11}$ & $n_{12}$ \\
\hline 2 & $n_{2}$ & $n_{21}$ & $n_{22}$ \\
\hline
\end{tabular}

Nilai apparent correct classification rate dihitung dengan menggunakan persamaan berikut (Rencher, 2002):

$$
\text { Ketepatan klasifikasi }=\frac{n_{11}+n_{22}}{n_{1}+n_{2}} \times 100 \%
$$

\section{Metodologi Penelitian}

\section{Data dan Variabel}

Data yang digunakan pada penelitian ini adalah data indikator IPM tahun 2015 pada setiap kabupaten/kota di Indonesia. Data diperoleh dari website BPS setiap provinsi di Indonesia. Jumlah data yang digunakan adalah sebanyak 514 kabupaten/kota. Variabel yang digunakan terdiri dari 10 variabel independen dan 1 variabel dependen. Definisi variabel yang digunakan dapat dilihat pada Tabel 2.

\begin{tabular}{|c|c|}
\hline Variabel & Keterangan \\
\hline \multirow[t]{3}{*}{$\mathrm{Y}$} & Klasifikasi kabupaten/kota berdasarkan indikator IPM: \\
\hline & 1. Rendah 3. Tinggi \\
\hline & 2. Sedang 4. Sangat Tinggi \\
\hline $\mathrm{X}_{1}$ & Angka Harapan Lama Sekolah (HLS) (tahun) \\
\hline $\mathrm{X}_{2}$ & Rata-rata Lama Sekolah (RLS) (tahun) \\
\hline $\mathrm{X}_{3}$ & Angka Partisipasi Sekolah SMA (APS SMA) (\%) \\
\hline $\mathrm{x}_{4}$ & Persentase penduduk vang memiliki ijazah tertingoi S1/S2/S3 $\%$ ) \\
\hline $\mathrm{X}_{3}$ & Angka Harapan Hidup (AHH) (tahun) \\
\hline $\mathrm{x}_{0}$ & Persentase penolong kelahiran oleh tenaga medis (\%) \\
\hline $\mathrm{X}_{7}$ & Persentase balita yang memperoleh imunisasi campak (\%) \\
\hline $\mathrm{X}_{\mathrm{s}}$ & Pengeluaran per kapita (Rupiah) \\
\hline $\mathrm{X}_{9}$ & Persentase penduduk miskin $(\%)$ \\
\hline $\mathrm{X}_{10}$ & Persentase Tingkat Pengangguran Terbuka (TPT) (\%) \\
\hline
\end{tabular}

Tabel 2. Variabel yang digunakan

\section{Prosedur Analisis Data}

Langkah-langkah yang dilakukan dalam penelitian ini adalah sebagai berikut:

1. Melakukan eksplorasi data.

2. Membagi data menjadi dua bagian, $80 \%$ (411 kabupaten/kota) data sebagai data training dan 20\% (103 kabupaten/koya) data sebagai data testing.

3. Melakukan uji asumsi.

4. Estimasi koefisien fungsi pengelompokan kabupaten/kota.

5. Menghitung tingkat ketepatan klasifikasi.

6. Melakukan validasi fungsi pengelompokan.

7. Kesimpulan.

\section{Hasil dan Pembahasan}

\section{Analisis Deskriptif}

Untuk melihat gambaran masing-masing variabel digunakan analisis deskriptif. Nilai statistik deskriptif untuk masing-masing variabel yang digunakan pada penelitian ini dapat dilihat pada Tabel 3.

Tabel 3. Statistika deskriptif setiap variable

\begin{tabular}{crrr}
\hline Variabel & Rata-rata & \multicolumn{1}{c}{ Minimum } & \multicolumn{1}{c}{ Maksimum } \\
\hline $\mathrm{X}_{1}$ & 12,38 & 2,17 & 17,01 \\
$\mathrm{X}_{2}$ & 7,86 & 0,64 & 12,38 \\
$\mathrm{X}_{5}$ & 72,65 & 20,82 & 94,28 \\
$\mathrm{X}_{4}$ & 5,71 & 0,00 & 21,23 \\
$\mathrm{X}_{5}$ & 68,71 & 53,60 & 77,46 \\
$\mathrm{X}_{6}$ & 85,86 & 0,11 & 100,00 \\
$\mathrm{X}_{7}$ & 76,63 & 9,63 & 100,00 \\
$\mathrm{X}_{8}$ & 9.399 .676 & 3.625 .000 & 22.425 .000 \\
$\mathrm{X}_{9}$ & 12,62 & 1,68 & 45,74 \\
$\mathrm{X}_{10}$ & 5,62 & 0,34 & 17,26 \\
\hline
\end{tabular}

Berdasarkan Tabel 3 dapat dilihat bahwa terdapat jarak yang cukup jauh antara nilai maksimum dan minimum untuk setiap variabel. 


\section{Uji Asumsi}

\section{Uji Normal Ganda}

Pada Gambar 1 dapat dilihat bahwa plot untuk kelompok rendah cenderung membentuk garis lurus dan ada lebih dari $50 \%(56,25 \%)$ nilai $d_{j}^{2}<\chi_{0,5,10}^{2}$, sehingga dapat disimpulkan bahwa data cenderung berdistribusi normal ganda. Plot untuk kelompok sedang juga cenderung membentuk garis lurus dan terdapat lebih dari $50 \%(53,39 \%)$ nilai $d_{j}^{2}<\chi_{0,5,10}^{2}$. Begitu juga dengan plot kuadrat jarak mahalanobis dengan nilai chi-square untuk kelompok tinggi dan sangat tinggi yang juga cenderung membentuk garis lurus.

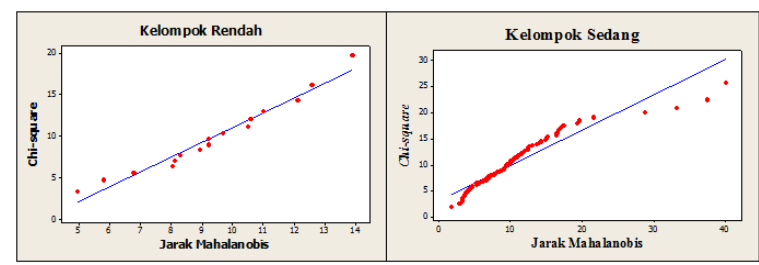

Gambar 1. Plotchi-square kelompok rendah dan sedang

Plot untuk kelompok tinggi memiliki lebih dari $50 \% \quad(57,28 \%)$ nilai $d_{j}^{2}<\chi_{0,5,10}^{2}$ dan untuk kelompok sangat tinggi juga memiliki lebih dari $50 \%(52,11 \%)$ nilai $d_{j}^{2}<\chi_{0,5,10}^{2}$, sehingga data cenderung berdistribusi normal ganda. Plot kuadrat jarak mahalanobis dengan nilai chi-square untuk kelompok tinggi dan sangat tinggi dapat dilihat pada Gambar 2.

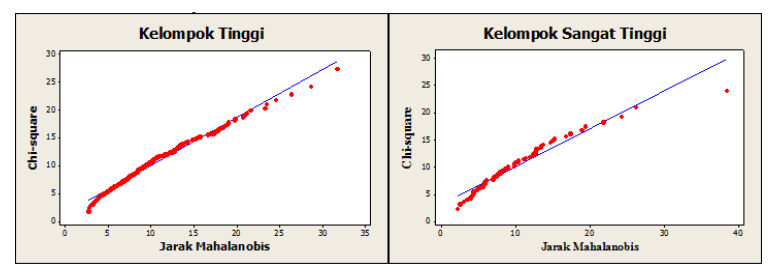

Gambar 2. Plotchi-square kelompok tinggi dan sangat tinggi

\section{Uji Kesamaan Matriks Peragam}

Hasil uji Box's $M$ menunjukkan bahwa nilai $p$ value $(0,000)$ lebih kecil dari $\alpha(0,05)$, sehingga keputusan pengujian $\mathrm{H}_{0}$ ditolak, yang berarti matriks peragam dari setiap kelompok berbeda. Asumsi kesamaan matriks peragam tidak terpenuhi. Oleh karena itu, dilakukan transformasi data menggunakan transformasi logaritma natural, sehingga diperoleh hasil uji kesamaan matriks peragam seperti pada Tabel 4.
Tabel 4. Hasil uji kesamaan matriks peragam

\begin{tabular}{ccccc}
\hline Box's $\boldsymbol{M}$ & $\mathbf{D b}_{1}$ & $\mathbf{D b}_{2}$ & $\mathbf{F}_{\text {hitung }}$ & $\begin{array}{c}\boldsymbol{P} \text { - } \\
\text { value }\end{array}$ \\
\hline 420,910 & 165 & 7155,483 & 0,917 & 0,072 \\
\hline
\end{tabular}

Nilai p-value yang diperoleh pada Tabel 4 adalah sebesar 0,072. Nilai p-value besar dari $\alpha$, yaitu $0,072>0,05$, sehingga keputusan pengujian tidak dapat menolak $\mathrm{H}_{0}$ yang berarti matriks peragam setiap kelompok adalah sama.

\section{Uji Beda Vektor Rata-rata}

Hasil uji beda vektor rata-rata dapat dilihat pada Tabel 5 yang menunjukkan bahwa nilai $p$-value $<$ $\alpha$, yaitu $0,000<0,05$. Berdasarkan hal tersebut keputusan pengujian adalah tolak $\mathrm{H}_{0}$, yang berarti terdapat perbedaan vektor nilai rata-rata variabel bebas antar kelompok, sehingga fungsi diskriminan dapat dibentuk.

Tabel 5. Hasil uji beda vektor rata-rata

\begin{tabular}{ccccc}
\hline $\begin{array}{c}\text { Wilks' } \\
\text { Lambda }\end{array}$ & $\mathbf{D b}_{1}$ & $\mathbf{D b}_{2}$ & $\mathbf{F}_{\text {hitung }}$ & $\begin{array}{c}\boldsymbol{P} \text { - } \\
\text { value }\end{array}$ \\
\hline 0,044 & 30 & 1168,885 & 74,032 & 0,000 \\
\hline
\end{tabular}

\section{Fungsi Diskriminan}

Analisis diskriminan yang dilakukan untuk pembentukan fungsi diskriminan adalah analisis diskriminan Fisher. Jumlah peubah yang digunakan untuk pembentukan fungsi diskriminan adalah 10 peubah. Jumlah data yang digunakan untuk pembentukan fungsi diskriminan adalah ada sebanyak 411 data dan sebanyak 103 data digunakan untuk validasi fungsi diskriminan. Fungsi diskriminan linear Fisher dapat dilihat pada Tabel 6.

Tabel 6. Koefisien fungsi diskriminan

\begin{tabular}{ccccc}
\hline \multirow{2}{*}{ Variabel } & \multicolumn{4}{c}{ Fungsi Klasifikasi } \\
\cline { 2 - 5 } & Rendah & Sedang & Tinggi & Sangat Tinggi \\
\hline Konstanta & $-55,35$ & $-3,22$ & $-1,21$ & $-9,52$ \\
$\ln \mathrm{X}_{1}$ & $-3,54$ & 0,18 & $-0,11$ & 0,62 \\
$\ln \mathrm{X}_{2}$ & $-2,73$ & $-0,64$ & 0,22 & 1,42 \\
$\ln \mathrm{X}_{5}$ & $-3,90$ & $-0,58$ & 0,31 & 0,90 \\
$\ln \mathrm{X}_{4}$ & $-0,64$ & $-0,48$ & $-0,84$ & 3,32 \\
$\ln \mathrm{X}_{5}$ & $-1,61$ & $-1,61$ & 0,46 & 1,64 \\
$\ln \mathrm{X}_{6}$ & $-7,20$ & $-1,01$ & 0,97 & 0,66 \\
$\ln \mathrm{X}_{7}$ & $-8,34$ & $-0,89$ & 0,72 & 1,36 \\
$\ln \mathrm{X}_{5}$ & $-1,50$ & $-0,94$ & $-0,18$ & 1,99 \\
$\ln \mathrm{X}_{9}$ & 6,64 & 0,65 & $-0,39$ & $-1,42$ \\
$\ln \mathrm{X}_{10}$ & $-3,41$ & $-0,94$ & 0,21 & 1,43 \\
\hline
\end{tabular}

Fungsi diskriminan dapat mengelompokan kabupaten/kota akan masuk ke dalam kategori status indikator IPM rendah, sedang, tinggi, dan sangat tinggi dengan melihat nilai skor diskriminan yang paling tinggi. hasil klasifikasi analisis diskriminan dapat dilihat pada Tabel 7 . 
Tabel 7. Ketepatan klasifikasi pegelompokan kabupaten/kota menggunakan analisis Diskriminan

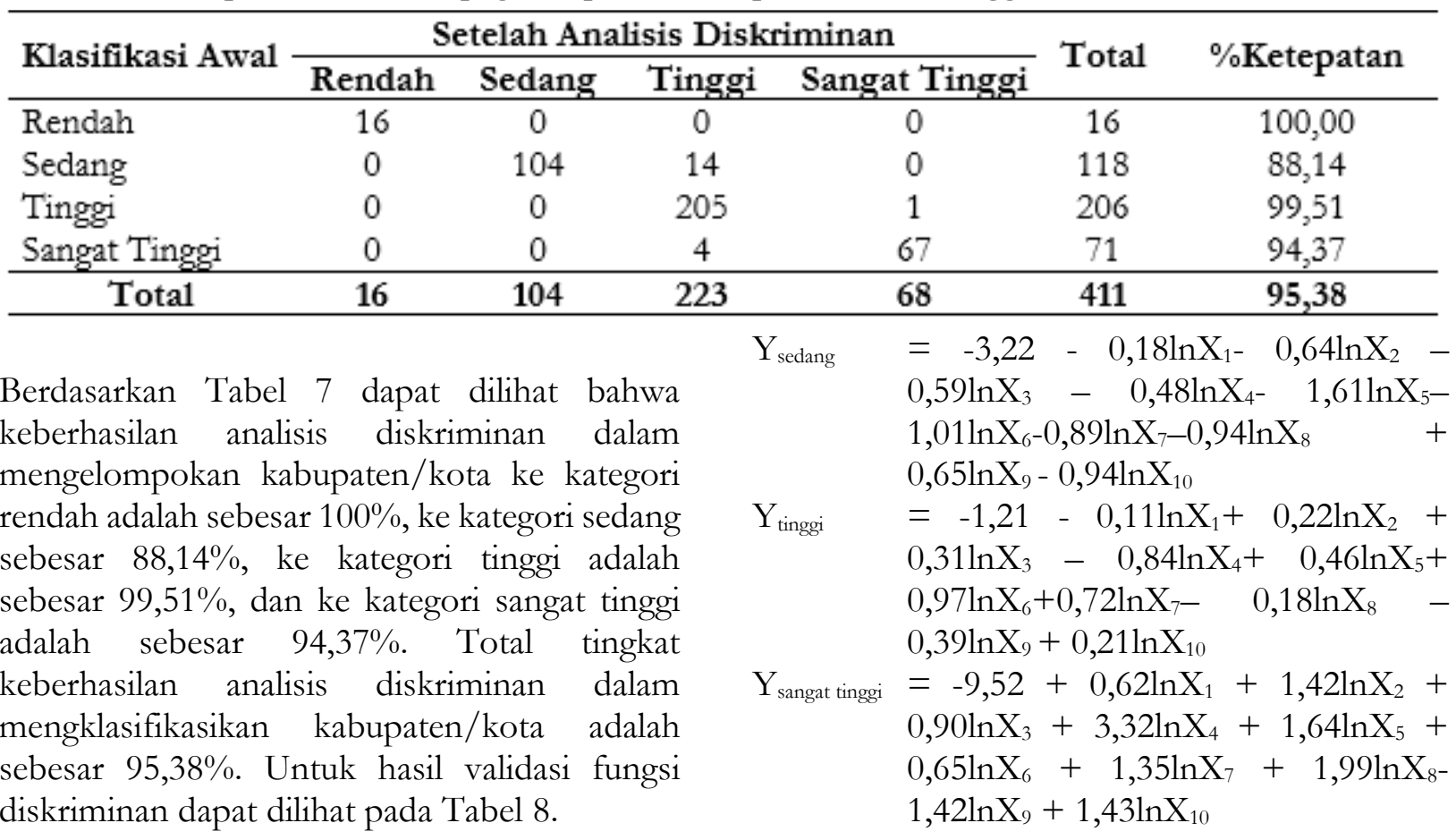

Tabel 8. Ketepatan pengelompokan data baru

\begin{tabular}{lccccccc}
\hline \multirow{2}{*}{ Kelompok Awal } & \multicolumn{5}{c}{ Analisis Diskriminan } & \multirow{2}{*}{ Total } & \multirow{2}{*}{ \% Ketepatan } \\
\cline { 2 - 5 } & Rendah & Sedang & Tinggi & Sangat Tinggi & & \\
\hline Rendah & 3 & 1 & 0 & 0 & 4 & 75,00 \\
Sedang & 0 & 25 & 5 & 0 & 30 & 83,33 \\
Tinggi & 0 & 1 & 51 & 0 & 52 & 98,08 \\
Sangat Tinggi & 0 & 0 & 0 & 17 & 17 & 100,00 \\
\hline \multicolumn{1}{c}{ Total } & $\mathbf{3}$ & $\mathbf{2 7}$ & $\mathbf{5 6}$ & $\mathbf{1 7}$ & $\mathbf{1 0 3}$ & $\mathbf{9 3 , 2 0}$ \\
\hline
\end{tabular}

Berdasarkan Tabel 8 diketahui bahwa dari 103 data yang digunakan, terdapat 96 kabupaten/kota $(93,20 \%)$ yang diklasifikasikan dengan benar sesuai dengan kelompok awal. Sebanyak 7 kabupaten/kota $(6,80 \%)$ salah diklasifikasikan. Dari hasil klasifikasi tersebut dapat diketahui bahwa kelompok yang tidak memiliki kesalahan dalam pengklasifikasian adalah kelompok sangat tinggi.

\section{Kesimpulan}

Fungsi diskriminan Fisher dengan menggunakan 10 peubah adalah sebagai berikut:

$\begin{array}{rlrrr}\mathrm{Y}_{\text {rendah }} & =-55,35-3,54 \ln \mathrm{X}_{1^{-}} & 2,73 \ln \mathrm{X}_{2^{-}} \\ & 3,90 \ln \mathrm{X}_{3^{-}} \quad 0,64 \ln \mathrm{X}_{4^{-}} & 1,61 \ln \mathrm{X}_{5-} \\ & 7,20 \ln \mathrm{X}_{6-} 8,34 \ln \mathrm{X}_{7^{-}} & 1,50 \ln \mathrm{X}_{8}+ \\ & 6,64 \ln \mathrm{X}_{9-}-3,41 \ln \mathrm{X}_{10}\end{array}$

Fungsi diskriminan tersebut dapat digunakan untuk mengelompokkan kabupaten/kota masuk ke dalam kategori status indikator IPM rendah, sedang, tinggi, dan sangat tinggi. Fungsi diskriminan Fisher yang digunakan cukup baik dalam megklasifikasikan setiap kelompok dengan tingkat keberhasilan lebih dari 85\%. Dan fungsi diskriminan tersebut didukung dengan tingkat keberhasilan validasi yang cukup baik juga.

\section{Daftar Pustaka}

BPS. (2015). Indeks Pembangunan Manusia 2015. Badan Pusat Statistik, Jakarta.

BPS. (2016). Indeks Pembangunan Manusia Provinsi Aceh 2014-2015. Badan Pusat Statistik, Banda Aceh. 
Hair, J. F., Black, W. C., Babin, B. J., \&Anderson, R. E. (2010). Multivariate Data Analysis a Global Perspective 7th ed. Pearson Prentice Hall, New Jersey.

Han, J., \& Kamber, M. (2006). Data Mining Concepts and Techniques 2nd ed. Elsevier Inc, United States.

Johnson, R.A., \& Wichern, D.W. (2007). Applied Multivariate Statistical Analysis 6th ed. Pretince Hall Inc, United States
Mattik, A. A., \& Sumertajaya, I. M. (2011). Sidik Peubah Ganda dengan Menggunakan SAS. IPB Press, Bogor.

Rencher, A. C. (2002). Methods of Multivariate Analysis 2nded. John Wiley \& Sons, Inc, United States. 